\title{
Papel da Província no Simbolismo Brasileiro
}

\section{Cassiana Lacerda Carollo}

Ainda que acreditemos estar a verdadeira definição e caracterizaçāo da literatura brasileira ligada ao processo de revisão do nosso passado a partir de autores e obras que contribuiram, definitivamente, para a ampliação e renovação de formas poéticas, o enfoque do mesmo problema através da evolução do pensamento crítico, paralelamente à nossa cultura, incita-nos às mais variadas consideraçōes.

Os fatores locais que dificultam uma designação genérica àquele período que o professor Dr. José Aderaldo Castelo chama de eclético, talvez justifiquem, em parte, da colocação do adjetivo brasileiro, de maneira a distinguir do contexto universal o Realismo, Naturalismo, Parnasianismo e Simbolismo.

Este ultimo, por ter sido o movimento que mais tem sofrido as consequências de abordagens deformadas, merece maior pesquisa por exigir ainda do estudioso a posição que Eduardo Portella chama de "pensar a literatura brasileira brasileiramente". 1

As "contradições internas", quando encaradas através da imposiçāo de uma realidade brasileira, poderão responder se no Brasil o Simbolismo representa o resultado final de uma evolução iniciada com o romantismo, e se foi como quer Arnold Hauser, em certos aspectos "uma reação a tôda poesia anterior". ?

A estas cogitações liga-se a observação, aceita por muitos, de que "a história literária de nosso tempo é grandemente a do desenvolvimento do Simbolismo e de sua fusão ou conflito com o Naturalismo". ${ }^{\text {a }}$

Esta fusāo/conflito, em nossa poesia parnasiana pode ser satisfatòriamente, explicada "pela índole romântica de seus cultivadores", decorrente não só da constância do romantismo entre nós, como pela presença de um modo de sentir caracteristicamente nacional.

Se a objetividade da escola importada, entrou em choque com a sensibilidade local, seria perfeitamente compreensível a fusão par- 
nasianismo-simbolismo, na medida em que êste último representa o desenvolvimento de um veio romântico, não possuindo em linhas gerais feição antinômica ao nosso feitio.

Independente das razões estéticas de certas impregnações interessam-nos aqui os problemas e conflitos locais que provocaram o insulamento da poesia simbolista brasileira, que para muitos passou desapercebida, e até acusada de "pura importação", não exercendo a função relevante que a distinguiu, desde o princípio, na literatura européia. ${ }^{4}$.

O que parece ter havido na abordagem do desenvolvimento dêste período, é o mal entendimento entre fatos de arte e fatos de vida, na consideração dos problemas de orientação da função verbal da literatura e a expansão inversa da liferatura na sociedade. Seria o caso de maior e melhor enfoque para o que Tynianov chama "correlação da literatura com as séries vizinhas". "

Nos conflitos de orientação dos parnasianos e simbolistas, observaremos não só o permanente processo de submissẽo das intençōes às necessidades de criação, mas a presença das possibilidades e condições locais.

Na fusão/conflito merecem ser apreciados os fenòmenos particulares ou de condições objetivas se impondo, critério êste que só acreditamos ser válido no estudo evolutivo da série literáriá.

A acusação feita ao simbolismo de haver passado ao largo dos acontecimentos, enquanto que os parnasianos mostraram-se participantes da realidade brasileira, em nada esclarece a função verbal de ambos os movimentos.

Se com o simbolismo vemos alargado "o hiato existente entre a praxis e a atividade artística", irara-se exatamente da intensificação de algo já existente nos postulados da poesia parnasiana. "

Porém se considerarmos o fenômeno inverso, ou seja, a prọ̣eção da literatura na vida social, veremos que grande parte das contradições se explicam por condicionamentos sociais particulares que permitiram tais expansōes.

Tais condiçães tem no depoimento de José Veríssimo uma res. posta significativa:

"Mais, talvez, do que nenhum outro aspecto da vida social, ressente-se a literatura de condiçāes do meio e do momento. Isto posto, não era de esperar que a nossa 
vida literária tivesse no ano de $1901 \ldots$ mais vigor, mais intensidade, mais riqueza e brilho do que teve..." o

A valorização do Rio de Janeiro, como centro da "literatura sorriso da sociedade", está ligada em têrmos de liderança à atividade dos poetas parnasianos, que representaram então a literatura oficial, cuja crosta o simbolismo não conseguiu romper para maior projeção.

E neste sentido, acreditados, estar apoiada a valorização da luta de grupos, dos conflitos que prepararam o advento do modernismo. Não se trata portanto de encarar o movimento simbolista no panorama da evolução da literatura brasileira, através da perspectiva da alienação/participação, mas do conflito literatura oficial a literatura marginal.

Enquanto o "Rio civiliza-se", acreditamos já se fazer necessário assinalar com maior desłaque o papel da província, não só para o estudo das contradições e conflitos, como pelo que se refere à história das idéias no Brasil e à projeção dos grupos simbolistas nos centros menores.

Por outro lado, se em outras épocas os periódicos "congregaram esforços, definiram a existência de grupos dando expressão à nossa vida literária", já tendo sido desłacado o papel da Revista Brasileira, Fon-Fon e das revistas simbolistas: Rosa Cruz, Anais, Kosmos, Mercúrio e Renascença, é importante acrescentar a estas o número expressivo de revistas literárias publicadas em outros Estados, em particular aquelas do Paraná: O Cenáculo, Clube Coritybano, Revista Azul, Jerusalém, Esphynge, e ainda Galáxia, A Penna, Pallium, e Breviário, Azul, Turris Eburnea, Victrix, Stellario, Brasil Cívico, Ramo de Acácia, que não só representam o maior número de periódicos do simbolismo, como sāo o repositório mais importante de seus textos, assinalando as contradiçōes marcantes deste movimento decorrentes do ecletismo de orientação, fato básico para compreensão do simbolismo brasileiro. ${ }^{8}$

Além disso, o prestígio literário de um Dario Velloso, Emiliano Pernetta, Silveira Neto, oficializam a literatura simbolista na provín. cia, através de um fenômeno significativo de expansāo social. "

Esta possibilidade permitiu ao simbolismo paranaense mostrar uma face nova do movimento que parecia estar condenado, pelos próprios postulados ao afastamento da realidade e dos problemas locais.

Apesar do horror à vulgaridade e ao comportamento burguês, 
os simbolistas paranaenses empenham-se na luła, mesmo que utópica, pela liberdade de pensamento, socialismo, anti-clericalismo e pacifismo, pertencendo algumas das revistas, como é o caso de Jerusa. lém, Esphynge, Ramo de Acácia, Brasil Cívico, ao capítulo da hitória das idéias.

Curitiba não só foi o mais radical dos centros simbolistas, como centralizou o movimento brasileiro através de 0 Cenáculo, durante o período $1895-7$.

No entanto, esta revista além de haver publicado textos do Luar de Hinverno de Silveira Neto, de Dario Velloso, Nestor de Castro, Emiliano Pernetta, Jean Itiberê, de colaboradores de outros estados como Gustavo Santiago, Antonio Austregesilo, Luiz Murat, e ainda do belga Ivan Gilkin, também acolheu Emílio de Menezes, Justiniano de Melo, Alberto Rangel, Antonio Braga e Leoncio Correa.

Mais do que um periódico expressivo do movimento, 0 Cenáculo revela suas preocupaçōes e convivências contraditórias, ainda que apresente uma evolução para idéias estéticas mais definidas em seu último ano de existência.

Bastante significativo é o programa incluído no primeiro número:

"O Cenáculo não vem pugnar dogmàticamente por nenhuma escola filosófica ou literária, porquanto não admite o exclusivismo partidário, nem reza litùrgicamente as litanias salmodiadas pelo fanatismo ortodoxo: quer Sentimento pelo Sentimento é a Verdade pela Verdade. Procurará, corajosamente, aproveitando os minereos - heterogeneos embora *, que constituirão quiçá o período primordial da literaturaconcorrentes também ao certame científico-literário *, que já se vai acentuando em alguns dos demais Estados da República".

De caráter científico são os ensaios incluidos nos primeiros números: Os instintos, A Libertaçāo da mulher, por Justiniano de Mello, Constituiçāo Fisica da América do Sul por Ernesto Luiz de Oliveira, A Evoluçāo, por Carvalho de Mendonça, o Vegetarismo por Alfredo Munhoz, O Progresso das Idades, por Romário Martins. Além disso, junta-se outro fato básico para avaliação desta revista, que é de formação do grupo, contido no testemunho de seus fundadores Dario Velloso e Silveira Neto.

* O grifo é meu. 
Este último, em artigo publicado na revista do Club Coritybano ${ }^{10}$ relata o desenvolvimento do grupo, que na realidade se formara já em 1893.

Foi na revista literária do Club Coritybano e nas reuniōes no Karoim subterrâneo de Dario Velloso que a amizade entre Silveira Neto, Antônio Braga e Julio Pernetta, foi se desenvolvendo.

Nessas reuniões segundo Silveira Neto, eram lidos Varella, Casimiro de Abreu, enquanto Dario Velloso, desde logo aparece interessado "na cabalística do verso".

Ao grupo inicial junta-se Rocha Pombo, Domingos Nascimento, (Diretor da Revista Azul "que vem totalizar e estreitar os esforços do grupo") Alberto Rangel, Leôncio Correia, sendo o visitante mais importante, segundo Silveira Neto, Luiz Murat.

A evolução e presença dessas amizades e interêsses podem ser ilustradas pelos textos publicados na revista do Club Coritybano. Revista, que acolheu as mais diversas tendências, não possuindo em seus 13 anos de existência, uma linha definida, mesmo sendo o maior repositório de textos e informaçōes do movimento cultural paranaense. Publicada desde 1890, incluiu na seção literária de nome Parnaso, publicaçōes de Castro Alves, Gonçalves Dias, Bilac, Raimundo Correia, Vicente de Carvalho ao lado de colaboraçōes de Mario Pederneiras, Nestor Vitor, Dario Velloso, Carlos D. Fernandes, Carlos Raposo, Alfredo Sarandy, Pereira da Silva, Gustavo Santiago, Antônio Austregésilo.

Assim como no caso de O Cenáculo é a partir de 1.897 que as tendências simbolistas se fazem mais marcantes.

O testemunho de Dario Velloso sôbre a formação do citado grupo, completa o quadro destas preocupaçōes e divergências. Das leifuras no subterrâneo, as que mais o impressionaram, parece não ter sido aquela dos românticos, mas desde logo, "as missas negras de Huysmans", os sabás de Michelet, Papus e Guaita.

"Foi no Cenáculo, diz êle a Silveira Neto, "saiste a combater a Serpente Negra, no Cenáculo, ao tempo em que no Paraná assassinavam o silvicola sob as vistas indiferentes do govêrno, partiu o humanitário alarma: Pelos indios." 11

Mais adiante, confessa não poder terminar "sem preito ao célebre cenáculo de lusitano". Eça, Ramalho, Antero, Oliveira, sem esquecer as penetrações corajosas na leitura de Darwin, Conte, Spencer, Leconte de Lisle, a luta contra o anti-feminismo, a defesa que 
faziam por Dreyfus e Zola, e a amizade com Carlos Raposo, intensificada pelo interêsse comum na reabilitaçāo de Pitágoras.

As revistas que se seguiram como o caso de Galáxia (1897) órgão do centro Literário, que teve entre os fundadores, Emiliano Pernetta, já possui um programa definido:

"Galáxia é a flâmula simbolista sob a qual se virāo grupar os Cids vitoriosos da Idéia, é a hóstia de ouro elevada litùrgicamente por inspiradores levitas do Sonho, a magnificientíssima Isis da beleza artística". (Galáxia (1), 1897). (1900).

O mesmo se poderia dizer das revistas Palium (1898) e Breviário

"Em extasi de olhares infinitos para o alto entre a pompa heráldica das celebrações de Arte, seguimos romeiros do Ideal, pelos constados horizontes do Sonho, a conduzir o sagrado Pallium dos nossos Anseios para a dor e para os encantamentos da vida Suprema".

(Pallium (1): 8, set. 1890)

“(...) Villers de L'Isle Adam na prosa e Verlaine, no verso são as duas personalidades artísticas surpreendentes desta posiçăo do século (. . .)

No Brasil um dos espíritos que mais legitimamente representa esta fidalga geração de estetas, é, sem dúvida, o Artista (Emiliano Pernetta) cujo busto ilumina a página de honra do Breviário".

(Breviário (1) : 2,3 maio 1900 )

Aqui já sentimos um pensamento teórico formulado, podendo ainda, ser motivo de análises interessantes, os propósitos das revistas: Turris Ebumea, Azul, bem como a colaboração homogênea de A Penna, Victrix, Stellario.

Porém, é impossível ignorar o movimento que se desenvolveu, paralelamente, em Jerusalem (1898) e Esphynge (1899). A primeira refletindo tôdas as preocupaçōes liberais do momento, é leitura obrigatória para uma idéia das proporçōes do anticlericalismo em Curitiba. A segunda, visava iniciar o Brasil nas "Antigos Templos da Ciên. cia Oculta", preparando o país "para a grandiosa luz do século $\mathrm{XX}$ ".

Decorrentes destas linhas de pensamento, surgiram obras significativas e polêmicas porém, acreditamos merecer destaque por se 
tratar de caso isolado em nossa literatura, a obra Atlântida de Dario Velloso.

Sua publicação tardia (1938) em muito deve ter prejudicado a avaliação desta tentativa de uma "Epopéia cósmica", cuja concepção central liga-se à substituição da mitologia clássica e lendas nacionais por mitos ocultistas.

Trata-se de uma tentativa de inscrever as origens do Brasil em plano universal, conferindo-lhe "a missão histórica de espargir no Orbe, ensinamentos pacifistas, homogeneizando as raças humanas, formando tipo sintético da Espécie". ${ }^{12}$

Wilson Martins, observa que "a Atlântida é, em teoria, a nossa epopéia nacional, e faltou-lhe a espessura de um cabelo para situar-se no mesmo plano de tantos outros poemas legendários de que se orgulham escandinavos ou indus, hispano-americanos ou poloneses - e mesmo francêses". ${ }^{13}$

- Simbolismo paranaense pelas condiçōes especiais em que se desenvolveu, permitindo a oficialização de uma atmosfera de sonhos e utopias, tornadas por um instante atualidade, impõe aos estudiosos de nossa historiografia literária maior interêsse pelos levantamentos regionais, em uma perspectiva de que surjam estudos sincrônicos dêste perlodo.

\section{NOTAS}

(1) PORTELla, Eduardo. Literafura - Realidado Brasiloira. Rio, Tempo Brasileiro, 1971, p. 32.

(2) HAUSER, Arnold. História Social do In Litepatura y al Arle. trad. espanhola, 3.a ed. Ma. drid, Guadanarra, 1964, $\vee$ II, p. 430.

(3) WILSON, Edmund. O Castelo de Axel. Säo Paulo, Cultrix, 1967. p. 24.

(4) Em sou trabalho Introdusão ao Extudo da Literalura Brasileira, monografia apresentads ao Eneontro Internacional de Estudos Brasileíros e I Seminário de Estudos Brasileiros (Säo Paulo, set. 1971), o prof. Dr. José Aderaldo Castelo ló salienta o papel do simbolisma na "intensificaçāo da preocupaçăo cstćlica, teárica, entro nós, e que deu o primeiro grande exemplo de lusas de geraçăo, o que vemos igualmente nos primeiros momentos do modernismo brasileiro".

(5) TYNIANOV, J. Da Evoluçăo Literária, In: TYNIANOV, J. el allii. Teoría da Literatura Formalistas Russos. Porto Alegre, Globo, 1971. p. 114.7.

(6) BOSI, Alfredo. O Simbolismo, In: - . História Concisa da Litoratura Brasileira. Sāo Paulo, Cultrix, 1971. p. 300.

(7) VERISSIMO, José. Estudos da Líteratura Brasiloirs. 4.a série, Rio, Garnier, 1910, p. 257.9.

(B) Ao elassificar os revistas simbolistas Andrado Muricy, em seu Panopáma do Simbolismo Brasileiro, p. 301-8, aponta entre as 29 revistas ligadas ao simbolismo, 16 edisadas no Pa. ranb.

O número 6 por si mesmo expressivo para impor um papel de destaque ao Parant. Há que considerar alnda, que das 13 restantes, 6 não pertencem a metrópole.

Porém, faz-se necessária no caso paranaense, a corroçajo de certos dados: A revisfa 
Pallium teve o seu primeiro número cditodo em 1898 (AM 1900) o mesmo se dá com Victrix, fundada em 1902 e näo em 1907.

Quanto a revista (sie) Actícia, trato-se de jornal moģonico que não passou do primeiro número.

Desde que êste periódico foi classificado como simbolista, ou que interessa a história do simbolismo, conviria assinalar outros de muito maior importancia e continuidade co. mo: Ramo de Acácia (Órgāo da Maçonaria do Paraná 1908-1912), Mirto o Acácia (Órgio do Instituto Néo.Pitagórico 1916-1920. Brasil Civico (1918) Electra (Órgāo Anti Olerieal. 1901-3) O Policano (Orgāo de Propaganda Muçonica - 1897.

Desfacam-se, ainds, como repositório de lextos esparsos o Almanach do Parane (1096-8) Almanach Paranaenso (1896-1901).

Outros periódiccs poderiam ser citados como documentos para pesquisa da formaçäo romántica dos autores paranaenses: O Mosqueteiro (1886-7) fundado por Dario Vellaso (manuscrito), A luta (1885-7), Revista do Paraná (1887), O Santelmo (188), A Idéia (1888.9). - Guarany (1891), O Fuluro (1892).

Outro dado interessante sóbre a históría dos periódicos paranaenses encontromos no número 17 da revista 0 Sapo, segundo o qual publicou.se no Paraná de 1854.1900 cêrca de 279 periódicos (alguns em polonês, alemão, e italiano os viltimos de caráter anarquists). dos quais 179 surgirsm cm Curitiba.

Na lista consta o nome de outras revistas liferárias, a além disso, notas da revista Club Coritybano assinalam ter sido fundado por Emiliano Pernelta e Silveira Neto o pe. riódico Cruzelro do Sul. Porém, estas ainda nāo foram localizedas.

(9) As proporçōes assumidas pela vida literária, e a mistifieaçāo do sưs personalioades, 6 um aspecto interessante o considerar como significaçāo no desenvolvimento literário. 0 critério de valor que vem sendo alribuido por estudiosos paranaense, a mesmo em certos trabalhos de Andrade Muricy (vide "Nova Hélado" Revista Brasileira de Cultura). torna esta dimensāo sccial da literafura nociva, no sentida de uma verdadeira colocação da literafura paronaenso.

(10) SIlveIRA Neto. O Cenáculo. Club Coritybano, Curisiba, (18): 3, 30 nov. 1894.

(11) Velloso, Dario. Do Retiro Szudoso. In: - - Obras. Curitiba, INP, 1969, p. 334-7.

(12) VEllosO, Dario. A Atlanlida. Curitiba, INP, 1939.

A gènese desta obra 6 bem mais longinqua do que 1933. En carta a Dario Velloso, Gonzaga Duque is cbserva que de Alma Paenitente a Althair vai surgir a grande obra de D. Velloso. (Carta publieada cm Club Coritybano (1) 1899).

Além de um glossário Atlantida apresenta uma vasta bibliografia que nāo só inclui os autores ocultistas - Papus, Lebesgue, Fabre D'Olivet, De Guaita, Flammarion, mas tam. bem Ernest Bose, Bernardino de Souza, Bilac, Domingos de Magalhāes, Euclides da Cunho, Alencar, Gonçalves Dias, Menotti del Picchia etc..

O curioso desta bibliografia é a consciöncia critica de sua elaboração.

(13) MARTINS, Wilson. O Universo de Simbolcs. Suplemento Lifertrio d' O Estado de Säo Paulo. Sao Paulo ( ): 4, 5 set. 1970. 